Organisational safety

\section{Organisations and safety in health care} R L Wears

$\mathrm{T}$ he role that organisations play in provoking or preventing accidents ${ }^{1}$ has been long studied in industry, but has only recently begun to gain attention in health care. But, understanding safety in complex socio-technical systems requires analysis at multiple levels, and each level is characteristically best approached by a different discipline. ${ }^{2}$ Because the relevant disciplines (such as sociology, anthropology, industrial psychology, macroergonomics, and organisational behaviour) are not easily accessible or well known, there is little opportunity for collaboration between them and the healthcare world. This led us to believe that an introduction to some of this work would be valuable to those concerned with improving the quality and the safety of health care.

This supplement has two main goals: firstly, to highlight the influence of higher level organisational factors so that they receive due regard from researchers, health professionals, and policy makers interested in improving patient safety. Secondly, to introduce a large body of theoretical and empirical work on organisational safety to groups who may not be familiar with this literature.

The papers in this issue fall into three natural groups. The first deals with organisational learning. Edmondson ${ }^{3}$ discusses reasons why it does not happen as often as it should in health care, while Rushmer and Davies ${ }^{4}$ deal with a related issue, how to unlearn lessons that were wrong, or are no longer relevant. Carroll and Quijada ${ }^{5}$ take a different approach to the same problem and suggest how traditional professional values might be usefully reinterpreted in ways that better support safety.

The second group of papers provides rich views of organisations and their behaviours as they attempt to achieve safe operations. Westrum ${ }^{6}$ provides a well known typology based on an organisations' response to information, particularly information about failure. Reason $^{7}$ describes a notorious organisational accident and directs our attention to the individuals trapped inside. Mohr et $a l^{8}$ point out that healthcare organisations are not monolithic, but have great heterogeneity. Schulman ${ }^{9}$ provides a high level view of how organisations approach failure free performance.

The third section deals with the organisations' leadership. Flin and Yule $^{10}$ give one model for leadership at varying levels in the organisation, while Weingart and Page ${ }^{11}$ describe the experience of healthcare chief executives in coming to grips with safety in their organisations.

The field of organisational safety in heterogeneous and complex. We can only give brief introduction to some of its general ideas within one supplement. We hope that those working in the world of health care-researchers, healthcare professionals, patients, workers, and organisational leaders-will be able to use the ideas, principles, and methods; concepts that are not new per se, but have not been well circulated in the world of healthcare and they too will see the possibility of collaborations in fields that they would not previously have imagined. Similarly, we hope that those in the world of organisational behaviour-sociologists, anthropologists, industrial psychologists, and others-will appreciate the immense challenges and opportunities that lie in what is probably the single most complex human endeavor in modern society, and act on those challenges by seeking entrée into healthcare settings for future study. Then the sorts of sustained, long term collaborations that will be necessary for real progress in safety can be formed. ${ }^{12}$

Qual Saf Health Care 2004;13(Suppl II):ii1. doi: 10.1136/qshc.2004.012732

Correspondence to: Dr R L Wears, Clinical Safety Research Unit, St Mary's Hospital, Praed Street, London W2 1NY, UK; r.wears@ imperial.ac.uk

\section{REFERENCES}

1 Reason J. Managing the risks of organizational accidents. Aldershot, UK: Ashgate Publishing Co, 1997.

2 Rasmussen J. Risk management in a dynamic society. Safety Science 1997;27:183-213.

3 Edmondson AC. Learning from failure in health care: frequent opportunities, pervasive barriers. Qual Saf Health Care 2004;13(Suppl ii):ii2-8.

4 Rushmer R, Davies HTO. Unlearning in health care. Qual Saf Health Care 2004; 13/Suppl ii):ii9-14.

5 Carroll JS Quijada MA. Redirecting traditional professional values to support safety: changing organisational culture in health care. Qual Saf Health Care 2004; 13(Suppl ii):ii15-20.

6 Westrum R. A typology of organisational cultures. Qual Saf Health Care 2004; 13(Suppl ii):ii21-6.

7 Reason J. Beyond the organisational accident: the need for "error wisdom" on the frontline. Qual Saf Health Care 2004;13(Suppl ii):ii27-32.

8 Mohr JJ, Batalden P, Barach P. Intergarting patient safety into the clinical microsystem. Qual Saf Health Care 2004;13(Suppl ii):ii33-7.

9 Schulman PR. General attributes of safe organisations. Qual Saf Health Care 2004;13(Suppl ii):ii38-43.

10 Flin R, Yule S. Leadership for safety: industrical experience. Qual Saf Health Care 2004;13(Suppl ii):ii44-50

11 Weingart SN, Page D. Implications for practice: challenges for healthcare leaders in fostering patient safety. Qual Saf Health Care 2004; 13(Suppl ii):ii51-55.

12 Cook RI, Woods DD. The messy details: insights from technical work studies in health care. In: Proceedings of the Human Factors and Ergonomics Society 47th Annual Meeting. Denver, CO: Human Factors and Ergonomics Society, 2003:379-80. 